\title{
A cross sectional evaluation of an alcohol intervention targeting young university students
}

Sharyn Burns ${ }^{1 *}$, Jonine Jancey ${ }^{1}$, Gemma Crawford ${ }^{1}$, Jonathan Hallett ${ }^{1}$, Linda Portsmouth ${ }^{1}$ and Janelle Longo ${ }^{2}$

\begin{abstract}
Background: Hazardous drinking has been found to be higher among young university students compared to their non-university peers. Although young university students are exposed to new and exciting experiences, including greater availability and emphasis on social functions involving alcohol there are few multi strategy comprehensive interventions aimed at reducing alcohol-related harms.
\end{abstract}

Methods: Random cross sectional online surveys were administered to 18-24 year old students studying at the main campus of a large metropolitan university in Perth, Western Australia. Prior to the completion of the second survey an alcohol intervention was implemented on campus. Completed surveys were received from 2465 (Baseline; T1) and 2422 (Post Year 1: T2) students. Students who consumed alcohol in the past 12 months were categorised as low risk or hazardous drinkers using the Alcohol Use Disorders Identification Test (AUDIT). Due to the cross sectional nature of the two samples two-tailed two-proportion z-test and two sample $t$-tests were employed to determine statistical significance between the two time periods for categorical and continuous variables respectively.

Results: At T1 and T2 $89.1 \%$ and $87.2 \%$ of the total sample reported drinking alcohol in the past month respectively. Hazardous levels of alcohol consumption reduced slightly between T1 (39.7\%) and T2 (38 \%). In both time periods hazardous drinkers reported significantly higher mean scores for experienced harm, second-hand harm and witnessed harm scores compared to low risk drinkers $(p<0.001)$. Hazardous drinkers were significantly more likely to experience academic problems due to their alcohol consumption and to report more positive alcohol expectations than low risk drinkers at both time periods $(p<0.001)$.

Conclusions: Harms and problems for students who report hazardous drinking are of concern and efforts should be made to ensure integrated and targeted strategies reach higher risk students and focus on specific issues such as driving while intoxicated and alcohol related unplanned sexual activity. However there is also a need for universal strategies targeting all students and low risk drinkers as they too are exposed to alcohol harms within the drinking and social environment. Changing the culture of the university environment is a long term aim and to effect change a sustained combination of organisational actions, partnerships and educational actions is required.

Keywords: Alcohol, University students, AUDIT, Alcohol-related harms, Alcohol-related problems, Alcohol expectancies

\footnotetext{
* Correspondence: s.burns@curtin.edu.au

'School of Public Health, Curtin University, GPO Box U1987, Perth, WA 6845,

Australia

Full list of author information is available at the end of the article
} 


\section{Background}

The transition period from secondary school to college or university has been identified as a particularly high risk period for a range of health compromising behaviours, including excessive alcohol consumption [1,2]. Many young university students drink alcohol at levels that place themselves and others at risk of a range of short and long term harms [3-7]. Hazardous drinking has been found to be higher among young university students in New Zealand compared to their nonuniversity peers [8] with suggestions that the university environment contributes to these differences $[8,9]$. Young university students are exposed to new and exciting experiences, including greater availability and emphasis on social functions involving alcohol [8]. This is an important developmental period during which many young people explore their identity and form more mature relationships [1]. In addition to these changes some students live away from their family home for the first time [8].

Significant increases in proportions of 12-17 year olds in Australia choosing to abstain from alcohol and fewer young people exceeding adult guidelines for single occasion risk between 2010 and 2013 demonstrate encouraging changes in alcohol consumption for school-aged students. However despite these encouraging findings young people aged 18-24 years were more likely to drink at harmful levels on a single occasion than other adult age groups [10]. These data support the ongoing need to provide positive and effective strategies to reduce levels of alcohol consumption and associated harm as young people move to tertiary education and the workforce.

Although the university has been identified as an ideal setting for health promotion interventions $[2,11]$, there is paucity of integrated, comprehensive interventions focusing on reducing alcohol-related harms among Australian universities described in the literature. Despite this, there have been interventions focusing on a single strategy, usually brief interventions, that have demonstrated some short term changes in alcohol consumption levels $[12,13]$ and alcohol related problems [12] however no significant differences were reported for alcohol-related harms [13].

This paper describes a university based alcohol intervention and compares low risk and hazardous drinking prevalence and experienced, second-hand, witnessed and academic harms for the total sample, and makes comparisons between low risk and hazardous drinkers at baseline and after the first year of the intervention. The paper will describe the effect of the intervention after year one.

\section{Theoretical basis of the youth alcohol project intervention} The Youth Alcohol Project (YAP) was implemented at a large and culturally diverse university campus in Australia with the aim of reducing the witnessed and experienced harms associated with alcohol consumption among 18-24 year old students. Social Cognitive Theory (SCT) was used to inform the development of the intervention. The underlying premise of SCT is reciprocal determinism, in particular the relationship between the individual, behaviours and the environment [14]. Individual traits such as personality, genetic factors and gender have been found to influence alcohol consumption and related behaviours [15-17]. The environment is a significant influence in initiation and drinking behaviours of young people $[16,17]$. The university environment which may include events that encourage excessive drinking and new peer networks [8] along with the belief that excessive alcohol use is a 'rite of passage' [18] and an integral part of the university experience [19] are important influences. Social and cultural norms which suggest for some young people drinking to get drunk is the main goal of many events and social occasions $[20,21]$ are often influenced by alcohol expectancies which are formed through social influences including family, peers and culture [22]. SCT recognises the power of observational learning such as the actions of peers and significant others [14] which is supported in the alcohol literature, recognising drinking behaviours are strongly influenced by the behaviours of peers, siblings and other family [15]. Norms and expectations help reinforce physical aspects of the environment including availability, promotion of alcohol and poorly implemented policy which together encourage excessive alcohol consumption $[8,15]$.

\section{The intervention}

The YAP was implemented using a multi-strategy staged approach. At year one (T1) data analysis some strategies had been only partially implemented. Commitment to a capacity building approach was adopted to embed strategies into university structures. Capacity building involves processes that build infrastructure, program sustainability and work to skill and empower individuals and groups $[23,24]$. The intervention includes a focus on organisational actions, partnerships and education actions. The strategies of the intervention are identified in Fig. 1 with their implementation status highlighted.

To coordinate and provide effective support to strategy implementation [24], partnerships were established with the Guild (student body), student support services, health services, security and housing personnel, campus venues such as taverns, cafes and sports clubs with licences to serve alcohol. These partnerships have worked to ensure more responsible promotion of alcohol on campus. The initiation and maintenance of a Local Drug Action Group (LDAG) (see http://localdrugaction.com.au) provides on going opportunities for community action, advocacy and education. During the first year of the intervention the 


\section{Capacity Building}
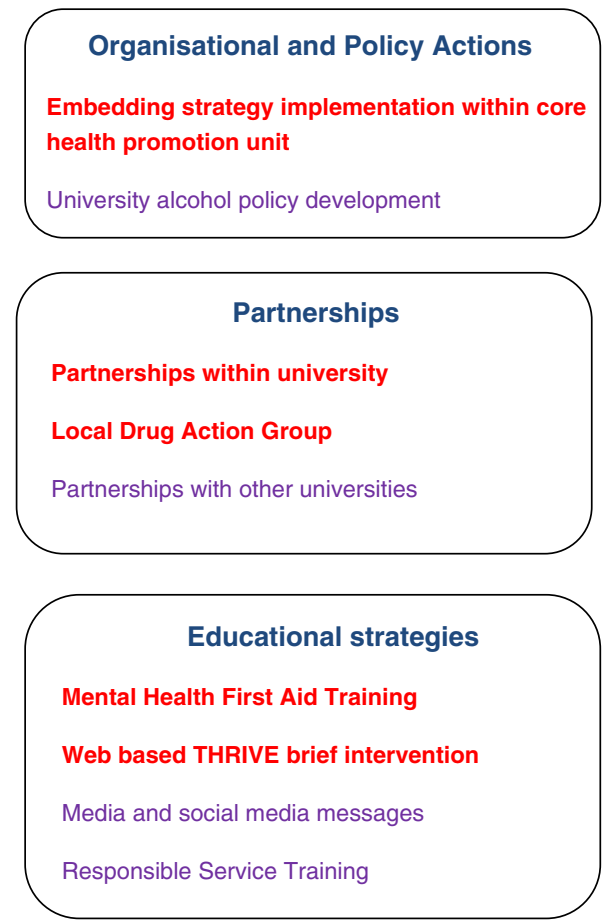

Strategies implemented prior to T2 data collection (red)

Strategies not yet implemented (purple)

Fig. 1 Intervention Strategies

LGAG produced an educational wallet card with first aid strategies for helping intoxicated friends and supported the Mental Health First Aid (MHFA) strategy.

Specific training, such as Responsible Service of Alcohol (RSA) training and MHFA were implemented to enhance the skills of the student community [25]. Provision of face-to-face Responsible Service of Alcohol training courses enhances skills and employability of students. These courses provide an additional opportunity for advocacy for responsible service, especially among clubs and groups. The adoption of responsible service practices was found to reduce levels of high risk drinking at community sporting clubs [26]. During the first year of the intervention two face-to-face RSA trainings were conducted with university sports club committee members $(n=30)$. Young university students have been found to experience higher levels of mental health problems than their peers [27] and high comorbidity with mental health problems and harmful alcohol consumption [28] reinforcing the importance of integrated strategies. MHFA aims to improve mental health literacy and to develop skills and confidence to provide help and referral in a mental health crisis or for ongoing mental health problems, including those related to alcohol and other drug use. The program has previously demonstrated effectiveness in the community [29], among university students [30] and workplaces [31]. During the first year of the intervention 295 students received MHFA training.

The web-based THRIVE (Tertiary Health Research Intervention Via Email) alcohol brief intervention, developed through this university and evaluated through a randomised controlled trial [13,32], was updated and integrated into the university website to provide an easily accessible and anonymous intervention for students. The program is a brief motivational health intervention consisting of an online alcohol assessment that delivers immediate and personalised feedback to participants on drinking behaviour, risks of harm, strategies for reducing consumption, and available support services for those drinking at harmful levels [13]. THRIVE is embedded in the student web portal and is voluntarily accessed. The program's referral system supports student transition to other existing interventions and alcohol and other drug counselling services provided through campus health services. Promotional strategies 
including the development of a bookmark distributed at campus events and web-based promotion were implemented to enhance the awareness of THRIVE.

To improve skills and empower young people the development of intervention strategies have been embedded into a core health promotion unit for undergraduate students. Students worked in small groups to develop, implement and evaluate a number of organisational actions, partnerships and educational actions. Embedding strategies within a unit supports sustainability and a committed group of project officers which stretches limited health promotion dollars further [33]. In the first year students worked on a range of projects linked to the ongoing strategies of the YAP.

The YAP is currently planning educational strategies with a focus on media and social media. Six focus groups were conducted with key stakeholders from the Tavern $(n=5)$, Security $(n=6)$ and students (four groups; $n=35$ students) to inform the development of educational strategies. Educational actions can be effective in improving knowledge, attitudes, skills and behaviours [23]. Based on the findings of the focus groups the intervention will utilise social media to facilitate positive change during the second year of the intervention Policy interventions are often integral to positive changes in health behaviour [34, 35]. The development and implementation of an alcohol policy is a current focus of the intervention.

\section{Methods}

Random cross sectional online surveys were conducted during July-August 2013 (baseline: T1) and 2014 (year 1: T2) in one university. The YAP commenced implementation after T1 data collection. For both time periods 6000 students aged $18-24$ years were emailed via their student email address by the University Surveys Office to invite them to participate in the study. Inclusion criteria required that the respondents' be studying at the main campus of the university and enrolled internally. In addition, random intercept surveys, administered by trained research assistants and completed online via i-pad, were conducted on campus market day (food and market stalls and activities) during the data collection period. Due to costs associated with data collection both surveys were cross sectional and a specific cohort was not followed. This study was approved by the Curtin University Human Ethics Committee (Approval no. HR 54/2013).

\section{Instrumentation}

Students were asked if they had drunk alcohol during the last 12 months [36]. Students who responded 'no' to this question did not complete the 10 item Alcohol Use Disorders Identification Test (AUDIT) [37] and the Alcohol Problems Scale [38] questions.
Consistent with other Australian studies the AUDIT scores were computed to binary variables low risk (non-hazardous; $<8$ ) and hazardous (risky; $\geq 8$ ) drinking $[5,6,13]$ to measure level of alcohol-related harm and consumption.

Harms experienced in the past 12 months were measured by the Alcohol Problems Scale, a 17 item scale of harms as a result of personal alcohol consumption) $[4,38]$. Students responded yes, no or prefer not to answer [score range 0-17] (See Table 4 for specific items). Second-hand harm, harms as a result of other students drinking during the past 4 weeks were measured using an 11 item scale [38, 39]. Witnessed harms, harms witnessed as a result of other students drinking during the past 4 weeks included a scale comprised of six harms [40]. For second-hand and witnessed harms students were provided with responses ranging from never to four or more times [score range $0-44$ and $0-24$ respectively with 0 representing no harm] (see Table 5 for specific items for second-hand and witnessed harms) [40].

The Academic Role Expectations and Alcohol Scale (AREAS) [38] included four items with responses ranging from not at all to four or more times during a four week reference period [score range 0-16]. The Brief Comprehensive Effects of Alcohol Scale (B-CEOA) [41] was used to measure alcohol expectancies. The scale included nine items with responses agree, neither agree or disagree or disagree [score range 9-27] (see Table 6 for specific items for AREAS and B-CEOA). Proportion of friends who regularly drink alcohol was measured to determine the influence of close peers on alcohol consumption.

Demographic data included age, gender, international or domestic student status, Faculty of enrolment (Business, Engineering and Science, Health Science or Humanities or Centre for Aboriginal Studies) and place of residence while at university (living in a shared house, with a parent or guardian, as a boarder or alone or with partner/children). The questionnaire was tested for face validity $(n=10)$ and content validity $(n=8)$. Test-retest was conducted with a purposive sample of the target group $(n=60)$. A detailed discussion of the development of this questionnaire and description of the variables can be found elsewhere [40].

\section{Data analysis}

The dependent variable for this study was the binary AUDIT score of low risk and hazardous drinking. Chi square analysis was used to determine statistical significance and proportions for categorical variables to compare low risk and hazardous drinkers at data collection periods. Analysis of Variance (ANOVA) was used to compute means and to determine statistical significance for continuous variables at each time period. Continuous variables included experienced, second-hand and witness harms, academic problems and alcohol expectancies. A 
two-tailed two-proportion z-test and two sample $t$-tests were employed to determine statistical significance between the two time periods for categorical and continuous variables respectively. Highly and moderately significant differences were discerned by $p$-values of $p<0.001$ and $p<0.05$ respectively [42].

\section{Results}

\section{Demographics}

At T1 1930 students responded to the online survey (32.2\% response rate) and a further 628 were recruited via intercept. At T2, 1825 (30.4\% response rate) responded online and 681 via intercept modes respectively. Completed surveys were received from 2465 (T1) and 2422 (T2) students. There was no significant difference between data collected online or via random intercept at $\mathrm{T} 1$ or $\mathrm{T} 2$.

Between T1 and T2 there was no significant difference between the proportions of students who responded in regard to gender, age, international or domestic student status, Faculty or place of residence (apart from slightly more students living with parents at T2 $(p<0.05)$. For both data collection time periods females were more likely to respond (62.1\%) (Table 1$)$.

\section{Hazardous vs low risk drinkers}

There were some significant differences in some demographics when current drinkers were categorised as low risk drinkers (<8 AUDIT score) or hazardous drinkers (> 8 AUDIT score) (Table 2). At T2 older students (2124 years) were less likely to be categorised as hazardous drinkers and more likely to be low risk drinkers compared to T1. There were significantly less international students and significantly more domestic students who reported hazardous drinking at T2 and significantly less domestic students who reported low risk drinking at T2.

\section{Reporting of alcohol consumption}

At T1 $89.1 \%$ and at T2 $87.2 \%$ of the total sample reported drinking alcohol in the past month. Hazardous levels of alcohol consumption reduced slightly between T1 (39.7\%) and T2 (38 \%) however these results were not statistically significant. There were no statistically significant differences in mean scores for a) experienced harms, b) witnessed and second-hand harms, c) academic problems or d) alcohol expectancies over the two time periods (Table 3 ). There were some moderately significant differences in the proportion of close friends who drank alcohol at each time period with more students reporting that none of their close friends drank alcohol (6.4 \% T2 vs $4.5 \%$ T1) and less students reporting most of their friends drank alcohol at T2 (40.7 \% T1 vs $37.7 \%$ T2) $(p<0.05)$.
Table 1 Demographics for the total sample at baseline and post 1

\begin{tabular}{llll}
\hline & $\begin{array}{l}\text { Baseline (T1) } \\
(2013)\end{array}$ & $\begin{array}{l}\text { Post 1 (T2) } \\
(2014)\end{array}$ & $\begin{array}{l}\text { significance } \\
(\mathrm{p}) \mathrm{T1} / \mathrm{T} 2\end{array}$ \\
\hline $\begin{array}{llll}\text { Gender } \\
\text { Male }\end{array}$ & $926(37.6)$ & $908(37.5)$ & 0.968 \\
$\quad$ Female & $1531(62.1)$ & $1504(62.1)$ & 0.992 \\
Other & $8(0.3)$ & $9(0.4)$ & 0.779 \\
Total & 2465 & 2421 & \\
Age & & & \\
18-20 years & $1191(48.3)$ & $1208(49.9)$ & 0.271 \\
$21-24$ years & $1275(51.7)$ & $1214(50.1)$ & 0.200 \\
Total & 2466 & 2422 &
\end{tabular}

International/domestic student status

$\begin{array}{llll}\text { International student } & 300(12.2) & 283(11.6) & 0.603 \\ \text { Domestic student } & 2166(87.8) & 2139(88.3) & 0.603 \\ \text { Total } & 2466 & 2422 & \\ \text { Faculty } & & & \\ \text { Health Science } & 918(37.5) & 876(36.2) & 0.441 \\ \text { Science and Engineering } & 552(22.4) & 541(22.3) & 0.968 \\ \text { Humanities } & 494(19.6) & 537(22.2) & 0.067 \\ \text { Business } & 496(19.7) & 462(19.1) & 0.363 \\ \text { Aboriginal Studies } & 6(0.2) & 6(0.2) & 0.976 \\ \text { Total } & 2466 & 2422 & \end{array}$

Place of residence while at university

$\begin{array}{llll}\text { Share flat/house } & 559(23.5) & 590(25.1) & 0.190 \\ \text { Student housing } & 105(4.4) & 114(4.9) & 0.465 \\ \text { Parent/guardian } & 1507(63.3) & 1418(60.3) & 0.038^{* *} \\ \text { Live alone } & 39(1.6) & 46(2) & 0.406 \\ \begin{array}{l}\text { With partner/children } \\ \begin{array}{l}\text { Board/live with other } \\ \text { relative or friend/other }\end{array}\end{array} & 114(4.8) & 128(5.4) & 0.303 \\ \text { Total } & 2382 & 54(2.3) & 0.756 \\ & & 2350 & \end{array}$

$*(p<0.001)$

$* *(p<0.05)$

Low risk versus hazardous drinkers and associated harms

Further analyses were conducted using the dependent variable low risk and hazardous consumption at each time period (Table 3). When harms (experienced; second hand; witnessed) and academic problems were compared there were little differences in total mean scores for all current drinkers, at $\mathrm{T} 1$ compared to $\mathrm{T} 2$. In both time periods hazardous drinkers reported significantly higher mean scores for experienced harm, second-hand harm and witnessed harm scores compared to low risk drinkers $(p<0.001)$. Of the total sample approximately $71 \%$ had experienced hangovers at both time periods. Hazardous drinkers were significantly more likely than low risk drinkers to have experienced unprotected sex 
Table 2 Demographics, harms and influencing factors for low risk and hazardous drinkers at the two time periods

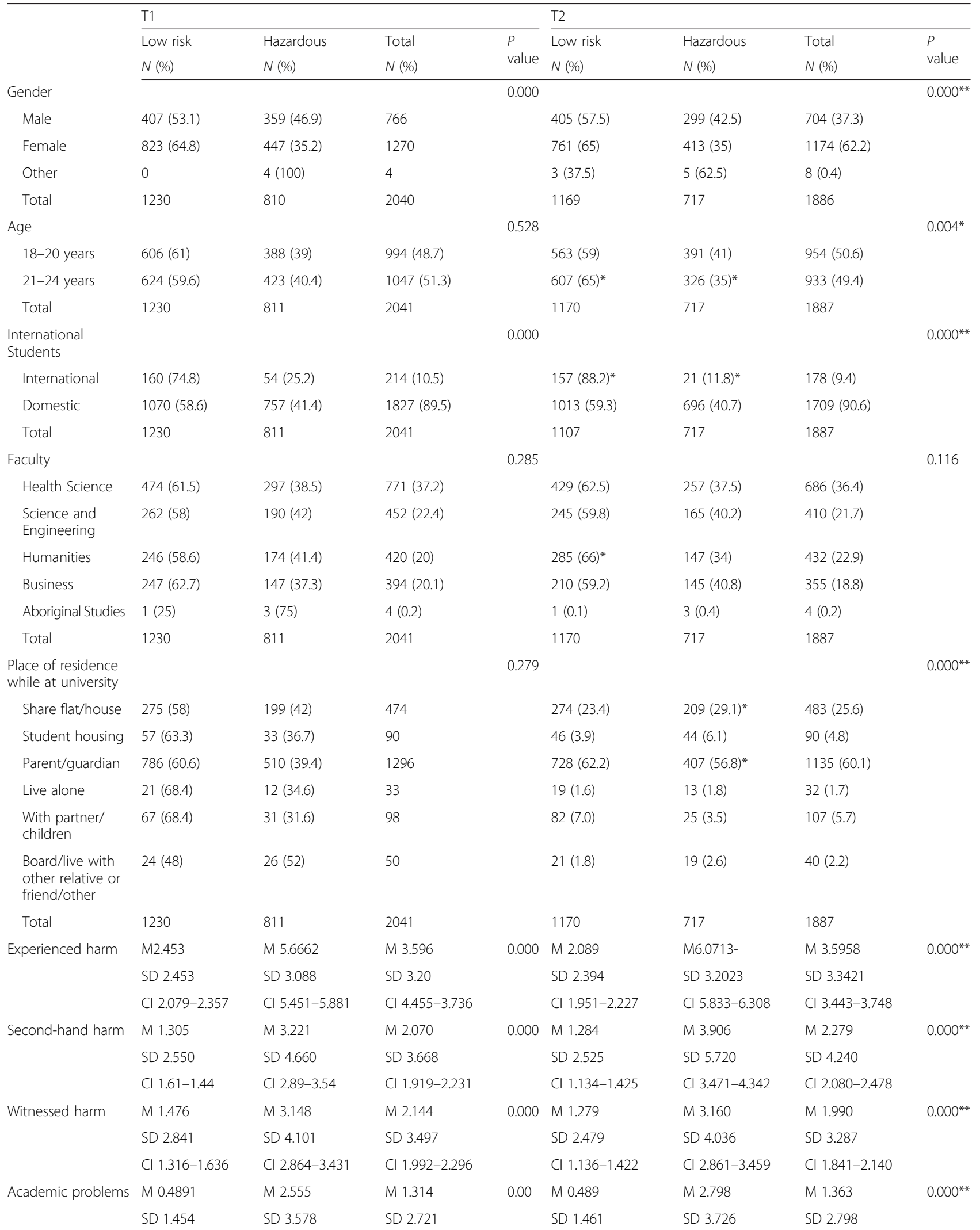


Table 2 Demographics, harms and influencing factors for low risk and hazardous drinkers at the two time periods (Continued)

\begin{tabular}{|c|c|c|c|c|c|c|c|c|}
\hline & $\mathrm{Cl} 0.406-0.571$ & Cl 2.307-2.804 & Cl 1.195-1.434 & & $\mathrm{Cl} 0.405-0.574$ & Cl 2.522-3.075 & Cl 1.235-1.490 & \\
\hline \multirow{3}{*}{$\begin{array}{l}\text { Alcohol } \\
\text { expectancies }\end{array}$} & M 21.110 & M 23.312 & M 21.985 & 0.000 & M 20.817 & M 23.555 & M 21.857 & $0.000^{* *}$ \\
\hline & SD 3.669 & SD 2.920 & SD 3.558 & & SD 3.990 & SD 2.964 & SD 3.869 & \\
\hline & Cl 20.905-21.315 & Cl 23.110-23.513 & Cl 21.830-22.139 & & Cl 20.588-21.0460 & Cl 23.337-23.772 & Cl 21.682-22.032 & \\
\hline $\begin{array}{l}\text { Friends who drink } \\
\text { regularly }\end{array}$ & & & & 0.000 & & & & $0.000^{* *}$ \\
\hline None & $34(2.9)$ & $4(0.5)$ & $38(1.9)$ & & $58(5.1)^{* * *}$ & $4(0.6)$ & $62(3.4)$ & \\
\hline A few & $432(36.2)$ & $87(11)$ & $519(26.2)$ & & 428 (37.6) & $65(9.4)$ & $493(27.0)$ & \\
\hline Half & $217(18.2)$ & $76(9.6)$ & $293(14.8)$ & & $192(16.9)$ & 87 (12.6) & 279 (15.3) & \\
\hline Most & $431(36.2)$ & 431 (54.6) & $862(43.5)$ & & 394 (34.6) & 358 (51.9) & 752 (41.1) & \\
\hline All & $78(6.5)$ & $192(24.3)$ & 270 (13.6) & & $67(5.9)$ & $176(25.5)$ & $243(13.3)$ & \\
\hline
\end{tabular}

${ }^{*} p<0.05$ between $\mathrm{T} 1$ and $\mathrm{T} 2 ;{ }^{*} p<0.001$ between $\mathrm{T} 1$ and $\mathrm{T} 2$

(Hazardous T1 34.5 \%; T2 35.4 \%; Low risk T1 9.35; T2 $9.6 \%)$ ), had driven a car while intoxicated (Hazardous T1 28.7 \%; T2 32 \%; Low risk T1 9.2 \%; T2 6.7 \%), were a passenger in a car where the driver was intoxicated (Hazardous T1 39.6 \%; T2 43.2 \%; Low Risk 11.1 \%; $10.7 \%$ ) and had been removed or banned from a club or pub because of their drinking (Hazardous T1 $22.8 \%$; T2 23.1 \%; Low Risk T1 5.4 \%; T2 4 \%) (Table 4). Hazardous drinkers were also significantly more likely than low risk drinkers to have experienced second-hand harms (as a result of other students drinking) such as being insulted or humiliated (Hazardous T1 28.5 \%; T2 $29.1 \%$; Low risk T1 $12.5 \%$; T2 $12.2 \%$ ) and taking care of another student who had drunk too much (Hazardous T1 44.4 \%; T2 48.4 \%; Low risk T1 27.5 \%; T2 $26.5 \%)$ ) (Table 5). Witnessing someone pass out (Hazardous T1 50.5 \%; T2 26.4 \%; Low risk T1 28.9 \%; T2 26.4 \%), a serious argument or quarrel (Hazardous T1 $41 \%$; T2 $21.3 \%$; Low risk T1 $17.9 \%$; T2 $15.7 \%$ ) and sexual assault (Hazardous T1 20 \%; T2 9.7 \%; Low risk T1 $9.5 \%$; T2 $9.7 \%$ ) was significantly more likely for hazardous drinkers compared to low risk drinkers at both time periods (Table 5).

Similarly hazardous drinkers were significantly more likely to experience academic problems at both time periods compared to low risk drinkers $(P<0.001)$. For example, at T1 and T2 42.8 and $45.6 \%$ of hazardous drinkers respectively indicated they had been unable to concentrate in class because of their drinking compared to $12.5 \%$ (T1) and $12.7 \%$ (T2) of low risk drinkers. Hazardous drinkers were more likely to report positive alcohol expectancies at both time periods $(p<0.001)$. These students anticipated alcohol would enable them to act more sociably (Hazardous T1 86.4 \%; T2 66.8 \%; Low risk T1 $72.4 \%$; T2 $66.8 \%$ ) and to have fun/ a good time (Hazardous T1 81 \%; T2 57.5 \%; Low risk T1 61.5; T2 $57.5 \%$ ) (Table 6).
Table 3 Drinking levels, harms and friends alcohol consumption for total sample at $\mathrm{T} 1$ and $\mathrm{T} 2$

\begin{tabular}{|c|c|c|c|}
\hline & $\begin{array}{l}\text { Baseline (T1) } \\
(2013)\end{array}$ & $\begin{array}{l}\text { Post } 1 \text { (T2) } \\
\text { (2014) }\end{array}$ & $\begin{array}{l}\text { significance } \\
\text { (p) } T 1 / T 2\end{array}$ \\
\hline \multicolumn{4}{|c|}{ Drunk alcohol in last 12 months } \\
\hline Yes & $2061(89.1)$ & $1905(87.2)$ & 0.051 \\
\hline No & $252(10.9)$ & $279(12.8)$ & 0.051 \\
\hline Total & 2313 & 2184 & \\
\hline \multicolumn{4}{|l|}{ AUDIT Score } \\
\hline Low risk & $1230(60.3)$ & $1170(62)$ & 0.262 \\
\hline Hazardous & $811(39.7)$ & $717(38)$ & 0.262 \\
\hline Total & 2041 & 1887 & \\
\hline $\begin{array}{l}\text { Experienced harm } \\
\text { score }\end{array}$ & M: 3.596 & M: 3.618 & 0.963 \\
\hline Total $n$ & 1995 & 1853 & \\
\hline $\begin{array}{l}\text { Second-hand harms } \\
\text { score }\end{array}$ & M: 2.0495 & M: 2.2270 & 0.999 \\
\hline Total $n$ & 2013 & 2013 & \\
\hline Witnessed harms score & M: 2.0500 & M: 1.8968 & 0.970 \\
\hline Total $n$ & 2013 & 2136 & \\
\hline $\begin{array}{l}\text { Academic problems } \\
\text { score }\end{array}$ & M: 1.3034 & M: 1.4544 & 0.963 \\
\hline Total $n$ & 1995 & 1853 & \\
\hline $\begin{array}{l}\text { Alcohol Expectancies } \\
\text { score }\end{array}$ & M: 21.5124 & M: 21.2314 & 0.965 \\
\hline Total $n$ & 2041 & 2184 & \\
\hline \multicolumn{4}{|c|}{ Friends who drink regularly } \\
\hline None & $99(4.5)$ & $134(6.4)$ & $0.005^{* *}$ \\
\hline A few & $619(27.9)$ & $615(29.3)$ & 0.327 \\
\hline Half & $322(14.5)$ & $308(14.7)$ & 0.896 \\
\hline Most & $902(40.7)$ & 792 (37.7) & $0.044^{* *}$ \\
\hline All & $275(12.4)$ & $252(12)$ & 0.681 \\
\hline Total & 2217 & 2101 & \\
\hline
\end{tabular}


Table 4 Experienced Harms and Level of Alcohol Consumption for Low Risk and Hazardous drinkers at T1 and T2

\begin{tabular}{|c|c|c|c|c|c|c|}
\hline & \multicolumn{3}{|c|}{ T1 $(n=1995)$} & \multicolumn{3}{|c|}{ T2 $(n=1853)$} \\
\hline & Low risk & Hazardous & Total & Low risk & Hazardous & Total \\
\hline & $N(\%)$ & $N(\%)$ & $N(\%)$ & $N(\%)$ & $N(\%)$ & $N(\%)$ \\
\hline Hangover & $692(57.8)$ & $729(91.5)$ & $1421(71.2)^{\mathrm{a}}$ & $668(58)$ & 647 (92.3) & $1315(71)^{b}$ \\
\hline Emotional outburst & $321(26.8)$ & $457(57.3)$ & $778(39)^{a}$ & $285(24.7)$ & $418(59.6)$ & $703(37.9)^{b}$ \\
\hline Vomiting & $486(40.6)$ & $584(73.3)$ & 1070 (63.6) & 422 (36.6) & $535(76.3)$ & $957(51.6)^{b}$ \\
\hline Heated argument & $139(11.6)$ & $315(39.5)$ & $454(22.8)^{a}$ & $157(13.6)$ & $304(43.4)$ & $461(24.9)^{\mathrm{b}}$ \\
\hline Physically aggressive & $45(3.8)$ & $162(20.3)$ & $207(10.4)^{a}$ & $44(3.8)$ & $147(21)$ & $191(10.3)^{b}$ \\
\hline Blackouts & $286(23.9)$ & $567(71.1)$ & $853(42.8)^{a}$ & $244(21.2)$ & $541(77.2)$ & $785(42.4)^{b}$ \\
\hline Inability to pay bills & $19(1.6)$ & $62(7.8)$ & $81(4.1)^{\mathrm{a}}$ & $14(1.2)$ & $67(9.6)$ & $81(4.4)^{b}$ \\
\hline Unprotected sex & $111(9.3)$ & $275(34.5)$ & $386(19.3)^{a}$ & $111(9.6)$ & $248(35.4)$ & $359(19.4)^{b}$ \\
\hline Sexual situation unhappy about at time & $57(4.8)$ & $118(14.8)$ & $175(8.8)^{\mathrm{a}}$ & $52(4.5)$ & $130(18.5)$ & $182(9.8)^{b}$ \\
\hline Sexual encounter later regretted & $98(8.2)$ & $237(29.7)$ & $335(16.8)^{\mathrm{a}}$ & $85(7.4)$ & $235(33.5)$ & $320(17.3)^{\mathrm{b}}$ \\
\hline Suffered an injury & $20(1.7)$ & $74(9.3)$ & $94(4.7)^{\mathrm{a}}$ & $18(1.6)$ & $74(10.6)$ & $92(5)^{\mathrm{b}}$ \\
\hline Drove a car & $110(9.2)$ & $229(28.7)$ & $339(17)^{\mathrm{a}}$ & $77(6.7)$ & $224(32)$ & $301(16.2)^{b}$ \\
\hline Passenger in a car & $133(11.1)$ & $316(39.6)$ & $449(22.5)^{a}$ & $123(10.7)$ & $303(43.2)$ & $426(23)^{b}$ \\
\hline Stole private or public property & $39(3.3)$ & $110(13.8)$ & $149(7.5)^{\mathrm{a}}$ & $28(2.4)$ & $111(15.8)$ & $139(7.5)^{b}$ \\
\hline Act of vandalism & $21(1.8)$ & $81(10.2)$ & $102(5.1)^{\mathrm{a}}$ & $20(1.7)$ & $85(12.1)$ & $105(5.7)^{\mathrm{b}}$ \\
\hline Removed or banned from a pub or club & $65(5.4)$ & $182(22.8)$ & $247(12.4)^{a}$ & $46(4)$ & $162(23.1)$ & $208(11.2)^{b}$ \\
\hline Arrested & $16(1.3)$ & $18(2.3)$ & $34(1.7)$ & $13(1.1)$ & $25(3.6)$ & $38(2.1)^{\mathrm{b}}$ \\
\hline
\end{tabular}

T1 Significant between low risk and hazardous drinkers $(p<0.001)^{\mathrm{a}}$ T2 Significant between low risk and hazardous drinkers $(p<0.001)^{\mathrm{b}}$

\section{Discussion}

Although the intervention had minimal impact during the first year the cross sectional nature of this evaluation provided only a limited analysis and it was difficult to determine differential effects of specific strategies. It is likely the staggered approach to the implementation of the strategies may have also impacted the findings. In addition, population based behaviour change is a complex and slow process [34]. Across both time periods the proportion of young university students who reported consuming alcohol at hazardous levels was high. There was a slight but not significant decrease in the proportion of current drinkers who reported hazardous drinking at T1 (39.7 vs $38 \%$ ). Analyses of the sample over the two time periods found hazardous drinkers were significantly more likely to experience harms as a result of their own alcohol consumption, to experience secondhand harms and to witness harms as a result of other students drinking.

There were no significant differences between almost all demographics variables respondents at $\mathrm{T} 2$ were moderately significantly more likely to live with their parents. A New Zealand study found students living in university residential accommodation or shared house to drink at higher levels than those living with parents [3]. This study found most students to live with parents (T1 $63.6 \%$; T2 $60.3 \%$ ) to live with parents in comparison $18.9 \%$ of respondents in the New Zealand study [3].
However these data are similar to that of another Australian university that found $54.9 \%$ of respondent lived with parents [5]. The university in this study is largely a commuter university which impacts the proportion of young people living at home.

The intervention did not impact significantly on harms associated with alcohol consumption however the high levels of harms experienced by those classified as hazardous drinkers' highlights the need for comprehensive strategies for this sub-group. While minimal intervention has been recognised as achieving some change, single strategy interventions are unlikely to have a significant impact on behaviour [34]. For example the webbased THRIVE alcohol brief intervention demonstrated positive short term results in reducing drinking frequency but found differences in alcohol-related harms to be non-significant [13]. Further exploration as how targeted promotion and personal referral could enhance this on line strategy for hazardous drinkers would be beneficial as well as research focusing on how such strategies can be extended to support long term behavioural change.

Alcohol expectancies remained similar across both time periods with students drinking at hazardous levels more likely to report positive expectancies. However, there was some reduction in the proportion of respondents reporting close friends consuming alcohol at T2. Associations between broad social motives, descriptive 
Table 5 Second-hand and Witnessed Harms and Level of Alcohol Consumption for Low Risk and Hazardous drinkers at T1 and T2

\begin{tabular}{|c|c|c|c|c|c|c|}
\hline \multicolumn{7}{|l|}{ Second-hand Harms } \\
\hline & \multicolumn{3}{|c|}{$\mathrm{T1}(n=2103)$} & \multicolumn{3}{|c|}{$\mathrm{T} 2(n=1861)$} \\
\hline & Low risk & High risk & Total & Low risk & High risk & Total \\
\hline & $n(\%)$ & $n(\%)$ & $n(\%)$ & $n(\%)$ & $n(\%)$ & $n(\%)$ \\
\hline Been insulted or humiliated & $149(12.3)$ & $229(28.5)$ & $378(18.8)^{a}$ & $141(12.2)$ & $205(29.1)$ & $346(18.6)^{b}$ \\
\hline Had a serious argument or quarrel & $87(7.2)$ & $180(22.4)$ & $267(13.3)^{\mathrm{a}}$ & $93(8)$ & $187(26.6)$ & $280(15)^{b}$ \\
\hline Been pushed, hit or otherwise assaulted & $44(3.6)$ & $109(13.6)$ & $153(7.6)^{a}$ & $35(3)$ & $105(14.9)$ & $140(7.5)^{b}$ \\
\hline Had your property damaged & $46(3.8)$ & $111(13.8)$ & $157(7.8)^{\mathrm{a}}$ & $52(4.5)$ & $119(16.9)$ & $171(9.2)^{b}$ \\
\hline Had to baby-sit or take care of another student who had drunk too much & $333(27.5)$ & $357(44.4)$ & $690(34.3)^{\mathrm{a}}$ & $307(26.5)$ & $341(48.4)$ & $648(34.8)^{\mathrm{b}}$ \\
\hline Found vomit in halls or bathroom of residence & $83(6.9)$ & $117(14.6)$ & $200(9.9)^{\mathrm{a}}$ & $78(6.7)$ & $144(20.5)$ & $222(11.9)^{b}$ \\
\hline Had studying or sleep interrupted & $236(19.5)$ & $275(34.2)$ & $511(25.4)^{\mathrm{a}}$ & $187(16.2)$ & $258(36.6)$ & $445(23.9)^{\mathrm{b}}$ \\
\hline Experienced an unwanted sexual advance & $103(8.5)$ & $178(22.1)$ & $281(14)^{\mathrm{a}}$ & $82(7.1)$ & $154(21.9)$ & $236(12.7)^{b}$ \\
\hline Been a victim of sexual assault (including date rape) & $11(0.9)$ & $25(3.1)$ & $36(1.8)^{\mathrm{a}}$ & $10(0.9)$ & $30(4.3)$ & $40(2.1)^{b}$ \\
\hline Been a victim of another crime on campus & $8(0.7)$ & $22(2.7)$ & $30(1.5)^{\mathrm{a}}$ & $11(1)$ & $30(4.3)$ & $41(2.2)^{b}$ \\
\hline Been a victim of another crime off campus* & $14(1.2)$ & $42(5.2)$ & $56(2.8)^{a}$ & $77(7.1)^{\mathrm{a}}$ & $110(16.4)$ & $187(10.6)^{b}$ \\
\hline \multicolumn{7}{|l|}{ Witnessed Harms } \\
\hline & \multicolumn{3}{|c|}{$\mathrm{T} 1(n=2013)$} & \multicolumn{3}{|c|}{$\mathrm{T} 2(n=1861)$} \\
\hline & Low risk & High risk & Total & Low risk & High risk & Total \\
\hline & $n(\%)$ & $n(\%)$ & $n(\%)$ & $n(\%)$ & $n(\%)$ & $n(\%)$ \\
\hline Someone being pushed, hit or otherwise assaulted & $217(17.9)$ & $271(33.7)$ & $488(24.2)^{\mathrm{a}}$ & $182(15.7)$ & $224(34.7)$ & $426(22.9)^{\mathrm{b}}$ \\
\hline Serious argument or quarrel & $274(22.7)$ & $330(41)$ & $604(30)^{a}$ & $246(21.3)$ & $288(40.9)$ & $534(28.7)^{b}$ \\
\hline Property damage & $136(11.2)$ & $225(28)$ & $361(17.9)^{a}$ & $150(13)$ & $194(27.6)$ & $344(18.5)^{b}$ \\
\hline Someone pass out & $349(28.9)$ & $406(50.5)$ & $755(37.5)^{\mathrm{a}}$ & $306(26.4)$ & $381(54.1)$ & $687(36.9)^{\mathrm{b}}$ \\
\hline Someone you suspect had alcohol poisoning & $122(10.1)$ & $189(23.5)$ & $311(15.4)^{\mathrm{a}}$ & $109(9.4)$ & $148(21)$ & $257(13.8)^{b}$ \\
\hline A sexual assault & $115(9.5)$ & $161(20)$ & $276(13.7)^{\mathrm{a}}$ & $112(9.7)$ & $147(20.9)$ & $259(13.9)^{\mathrm{b}}$ \\
\hline
\end{tabular}

$T 1$ Significant between low risk and hazardous drinkers $(p<0.001)^{\mathrm{a}}$ T2 Significant between low risk and hazardous drinkers $(p<0.001)^{\mathrm{b}}$

norms (the perception of what others do), personal drinking values and alcohol expectancies have been found to influence alcohol consumption and related harms among college students [43] and are consistent with Social Cognitive Theory which suggests behaviour is influenced by peers and expectations [14]. While there was little change between the two time periods this study found strong associations at both time periods between hazardous drinking and alcohol expectancies and associations between peer drinking and hazardous drinking, which demonstrate a need to focus on strategies that challenge descriptive and injunctive norms. Social acceptability of behaviours has been influenced positively through integrated and dedicated efforts at national, local and societal levels for issues such as smoking [34], however it is recognised that such changes take time and are most effective when a combination of educational, organisational, economic and political actions have been employed [35].

Many health promotion strategies are time consuming and complex and can be compromised if funded on short-term cycles [33]. This project had limited financial and personnel resources and as not all strategies of this intervention were implemented during the first year of the project. Organisational and policy actions have been identified as essential for effective health promotion $[23,34,35]$ and the development and implementation of alcohol policy is one of the strategies yet to be implemented. Effective policies in communities and organisations need to be well developed with considerable emphasis on the adoption and implementation phase $[44,45]$. Campus alcohol policy should reinforce and support responsible use of alcohol, reduce access, especially low cost and free alcohol, restrict heavy drinking on drinking premises and work to eliminate alcohol sponsorship on campus and in local communities to effect long term change [46]. From a population level it is recognised that comprehensive universal strategies that incorporate significant focus on policy are essential to effect change [47]. Policy implementation and promotion will be implemented as part of the ongoing intervention. In addition, strategies to build partnerships 
Table 6 Academic Problems and Alcohol Expectancies for Low Risk and Hazardous Drinkers at T1 and T2

\begin{tabular}{|c|c|c|c|c|c|c|}
\hline \multicolumn{7}{|l|}{ Academic Problems } \\
\hline & \multicolumn{3}{|c|}{ T1 $(n=1995)$} & \multicolumn{3}{|c|}{$\mathrm{T} 2(n=1853)$} \\
\hline & Low risk & Hazardous & Total & Low risk & Hazardous & Total \\
\hline & $N(\%)$ & $N(\%)$ & $N(\%)$ & $N(\%)$ & $N(\%)$ & $N(\%)$ \\
\hline Been late for a class & $87(7.3)$ & $242(30.4)$ & $329(16.5)^{a}$ & $78(6.7)$ & $225(32)$ & $303(16.3)^{b}$ \\
\hline Missed a class & $129(10.8)$ & $310(38.9)$ & $439(22)^{a}$ & $123(10.6)$ & $299(42.6)$ & $422(22.7)^{\mathrm{b}}$ \\
\hline Unable to concentrate in class & $150(12.5)$ & $341(42.8)$ & $491(24.6)^{a}$ & $146(12.7)$ & $320(45.6)$ & $466(25.1)^{\mathrm{b}}$ \\
\hline Failed to complete an assignment on time & $22(1.8)$ & $96(12)$ & $118(5.9)^{\mathrm{a}}$ & $23(1.9)$ & $104(14.8)$ & $127(6.8)^{b}$ \\
\hline \multicolumn{7}{|l|}{ Alcohol Expectancies } \\
\hline & \multicolumn{3}{|c|}{$\mathrm{T} 1(n=2041)$} & \multicolumn{3}{|l|}{$\mathrm{T} 2(n=$} \\
\hline & Low risk & Hazardous & Total & Low risk & Hazardous & Total \\
\hline & $N(\%)$ & $N(\%)$ & $N(\%)$ & $N(\%)$ & $N(\%)$ & $N(\%)$ \\
\hline Act more sociably & $891(72.4)$ & $710(86.4)$ & $1592(78)^{a}$ & $782(66.8)$ & $621(86.6)$ & $1403(74.4)^{b}$ \\
\hline Find it easier to talk to people & $880(71.5)$ & $680(83.8)$ & $1560(76.4)^{a}$ & 806 (68.9) & $626(87.3)$ & $1432(75.9)^{b}$ \\
\hline Feel calmer/more relaxed & $736(59.8)$ & $630(77.7)$ & $1366(66.9)^{a}$ & $679(58)$ & $559(78)$ & $1238(65.6)$ \\
\hline Enjoy sex more & $220(17.9)$ & $286(35.3)$ & $506(24.8)^{a}$ & $207(17.7)$ & $261(36.4)$ & $468(24.8)$ \\
\hline Take risks & $693(56.3)$ & $630(77.7)$ & $1323(64.8)^{\mathrm{a}}$ & $605(51.7)$ & $563(78.5)$ & $1168(61.9)^{b}$ \\
\hline Be more aggressive & $239(19.4)$ & $284(35)$ & $523(25.6)^{a}$ & $210(17.9)$ & $276(38.5)$ & $486(25.8)^{b}$ \\
\hline Feel more courageous & $680(55.3)$ & $599(73.9)$ & $1279(62.7)^{a}$ & $622(53.2)$ & $557(77.7)$ & $1179(62.5)^{b}$ \\
\hline Act loud, boisterous, noisy & $663(53.9)$ & $569(70.2)$ & $1232(60.4)^{\mathrm{a}}$ & $634(54.2)$ & $538(75)$ & $1172(62.1)^{\mathrm{b}}$ \\
\hline Have fun/good time & $757(61.5)$ & $657(81)$ & $1414(69.3)^{a}$ & $673(57.5)$ & $590(82.3)$ & $1263(66.9)^{b}$ \\
\hline
\end{tabular}

T1 Significant between low risk and hazardous drinkers $(p<0.001)^{\mathrm{a}} T 2$ Significant between low risk and hazardous drinkers $(p<0.001)^{\mathrm{b}}$

will be further developed in subsequent stages of this intervention. The establishment of partnerships and building capacity are time consuming and challenging however provide significant opportunities for change and will therefore be a focus of this intervention in the future [48].

The findings from the two data collection periods will help inform the development of additional strategies and provide evidence to support targeting specific subgroups e.g. those drinking at hazardous levels. However, although the findings indicate that while more prevalent among hazardous drinkers, experienced, secondhand and witnessed harms and academic problems are of concern for both the low risk and hazardous drinkers. These data are similar to findings elsewhere $[4,5]$ and confirm the need for enhanced education and awareness of these issues.

This study has a number of limitations which should be considered when interpreting the findings. The cross sectional nature of the study precludes casual assumptions and rigorous intervention evaluation however when implementing and evaluating interventions in communities there are practical and financial constraints which may preclude more rigorous evaluation strategies $[49,50]$. A cohort study, collecting data about recall of intervention strategies at $\mathrm{T} 2$, would provide a more rigorous evaluation, however was beyond the financial scope of this study [33]. Data were only collected from one university which may limit generalizability. Low response rates could have resulted in a non-respondent bias. Low response rates have been reported elsewhere [5]. It has been suggested non-respondents are more likely to participate in adverse health behaviours [3]. Self-report questionnaires may be subject to issues of social desirability, however comparisons with other studies suggest these data are reliable $[4-6,13]$.

\section{Conclusion}

The findings over the two year period confirm the need for on-going alcohol interventions for young university students. After one year this study found relatively small changes in prevalence of hazardous drinking levels and maintenance of alcohol related harms, expectancies and behaviours, however, a number of the intervention strategies had not been implemented or had only been partially implemented. These findings do however provide the opportunity to refine and focus strategies. Harms and problems for students who report hazardous drinking are of concern and efforts should be made to ensure integrated and targeted strategies reach higher risk students and focus on specific issues such as drink driving 
and alcohol related unplanned sex. However there is also a need for universal strategies targeting all students and low risk drinkers as they too are exposed to alcohol harms within the drinking and social environment. Changing the culture of the university environment is a long term aim and to effect change a sustained combination of organisational actions, partnerships and educational actions is required.

\section{Acknowledgements}

We would like to acknowledge Kristen Hunt who was the project officer for YAP. We would also like to acknowledge the participants of this study who gave their time to complete the survey, the Curtin Office for Strategy and Planning and health promotion students for help administering the survey. We gratefully acknowledge Healthway (The Western Australian Health Promotion Foundation) for funding this project.

\section{Availability of data and materials}

The datasets during and/or analysed during the current study available from the corresponding author on reasonable request.

\section{Author's contributions}

$\mathrm{SB}, J J, J H, G C$ have made substantial contributions to the conception and design of the paper. SB made substantial contributions to the data analysis. All authors were involved in planning and implementing the intervention. All authors reviewed the article for important intellectual content. All authors read and approved the final manuscript.

\section{Authors' information}

$\mathrm{SB}, J J, J H, \mathrm{GC}$ and LP conduct research within the Collaboration for Evidence, Research and Impact in Public Health at the School of Public Health, Curtin University. $J \mathrm{~L}$ is a health promotion practitioner within the South Metropolitan Public Health Unit

\section{Competing interests}

The authors declare that they have no competing interests.

\section{Consent for publication}

Not applicable.

\section{Ethics approval and consent to participate}

This study was approved by the Curtin University Human Ethics Committee (Approval no. HR 54/2013). Participants provided consent when they completed the online survey.

\section{Author details}

'School of Public Health, Curtin University, GPO Box U1987, Perth, WA 6845, Australia. ${ }^{2}$ South Metropolitan Population Health Unit, Department of Health, PO Box 546, Fremantle, WA 6959, Australia.

Received: 6 October 2015 Accepted: 15 July 2016

Published online: 20 July 2016

\section{References}

1. White HR. Reduction of alcohol-related harm on United States College campuses: the use of personal feedback interventions. Int J Drug Policy. 2006;17(4):310-9.

2. VanKim NA, Laska MN, Ehlinger E, Lust K, Story M. Understanding young adult physical activity, alcohol and tobacco use in community colleges and 4-year post-secondary institutions: a cross-sectional analysis of epidemiological surveillance data. BMC Public Health. 2010;10:208.

3. Kypri K, Paschall MJ, Langley J, Baxter J, Cashell-Smith M, Bourdeau B. Drinking and alcohol-related harm among New Zealand University students: findings from a national web-based survey. Alcohol Clin Exp Res. 2009;33(2): 307-14

4. Hallett J, Howat P, McManus A, Meng R, Maycock B, Kypri K. Academic and personal problems among Australian university students who drink at hazardous levels: web-based survey. Health Promot J Austr. 2013;24:170-7.
5. Rickwood D, George A, Parker R, Mikhailovich K. Harmful alcohol use on campus: impact on young people at university. Youth Studies Australia. 2011;30(1):34-40.

6. Hallett J, Howat P, Maycock BR, McManus A, Kypri K, Dhaliwal SS. Undergraduate student drinking and related harms at an Australian university: web-based survey of a large random sample. BMC Public Health. 2012;12:37.

7. Burns S. Sexual health, alcohol and the university environment: is there a need for sexual health promotion intervention? Sex Health. 2015;12(3):26971. doi:10.1071/SH14215.

8. Kypri K, Cronin M, Wright CS. Do university students drink more hazardously than their non-student peers? Addiction. 2005;100:713-7.

9. Hallett J, McManus A, Maycock B, Smith J, Howat P. Excessive drinking - an inescapable part of university life? A focus group study of Australian undergraduates. Open J Prev Med. 2014:4:616-29.

10. Australian Institute of Health and Welfare. National Drug Strategy Household Survey detailed report 2013. Drug statistics series no. 28. Cat. no. PHE 183. Canberra: AlHW; 2014

11. Crawford G, Freijah R, Wilkins A, Wylde P. Sex, Drugs and Mental Health: design and delivery of health promotion initatives in a university setting. Journal of the Australia and New Zealand Student Services Association. 2007:29:52-71.

12. Fachini A, Aliane PP, Martinez EZ, Furtado EF. Efficacy of brief alcohol screening intervention for college students (BASICS): a meta-analysis of randomized controlled trials. Subst Abuse Treat Prev Policy. 2012;7:40.

13. Kypri K, Hallett J, Howat P, McManus A, Maycock B, Bowe S, Horton NJ. Randomized controlled trial of proactive web-based alcohol screening and brief intervention for university students. Arch Intern Med. 2009;169(16):1508-14.

14. Bandura A. Social cognitive theory. In: Vasta R, editor. Annals of child development Vol6. Six theories of child development edn. Greenwich: JAI Press; 1989. p. 1-60.

15. Ahlström S, Österberg E. International perspectives on adolescent and young adult drinking. Alcohol Res Health. 2004/2005;28:258-268.

16. Rose RJ, Dick DM. Gene-environment interplay in adolescent drinking behavior. Alcohol Res Health. 2004;28(4):222-9.

17. Helene Raskin W, Jackson K. Social and psychological influences on emerging adult drinking behavior. Alcohol Res Health. 2004;28(4):182-90.

18. Glider P. Challenging the collegiate rite of passage: a campus-wide social marketing media campaign to reduce binge drinking. J Drug Educ. 2001; 31(2):207.

19. Osberg TM, Atkins L, Buchholz L, Shirshova V, Swiantek A, Whitley J, Hartman S, Oquendo N. Development and validation of the college life alcohol salience scale: a measure of beliefs about the role of alcohol in college life. Psychol Addict Behav. 2010;24(1):1-12

20. Fry M-L. Seeking the pleasure zone: understanding young adult's intoxication culture. Australas Mark J. 2011;19(1):65-70.

21. Hernandez L, Leontini R, Harley K. Alcohol, university students, and harmminimization campaigns: "A fine line between a good night out and a nightmare". Contemp Drug Probl. 2013;40(2):157-189,156.

22. Dunn ME, Goldman MS. Validation of multidimensional scaling-based modeling of alcohol expectancies in memory: age and drinking-related differences in expectancies of children assessed as first associates. Alcoho Clin Exp Res. 2000;24:1639-46.

23. Green LW, Kreuter MW. Health promotion planning: an educational and ecological approach. 4th ed. New York: McGraw Hill; 2005.

24. Joss N, Keleher H. Community development and partnerships. In: Keleher $H_{\text {, }}$ MacDougall C, editors. Understanding Health. 3rd ed. South Melbourne: Oxford University Press; 2011

25. Crawford G, Burns S, Chih HJ, Hunt K, Tilley M, Hallett J, Coleman K, Smith S. Mental health first aid training for nursing students: a protocol for a pragmatic randomised controlled trial in a large university. BMC Psychiatry. 2015:15:26. doi:10.1186/s12888-015-0403-3.

26. Kingsland M, Wolfenden L, Rowland BC, Gillham KE, Kennedy VJ, Ramsden RL, Colbran RW, Weir S, Wiggers JH. Alcohol consumption and sport: a cross-sectional study of alcohol management practices associated with atrisk alcohol consumption at community football clubs. BMC Public Health. 2013;13:762.

27. Stallman HM. Psychological distress in university students: a comparison with general population data. Aust Psychol. 2010;45(4):249-57.

28. Said D, Kypri K, Bowman J. Risk factors for mental disorder among university students in Australia: findings from a web-based cross-sectional survey. Soc Pyschiatry Pyschiatr Epidemiol. 2013;48:935-44. 
29. Jorm AF, Kitchener BA, O'Kearney R, Dear K. Mental health first aid training of the public in a rural area: a cluster randomized trial. BMC Psychiatry. 2004:4:33.

30. O'Reilly CL, Bell J, Kelly PJ, Chen TF. Impact of mental health first aid training on pharmacy students' knowledge, attitudes and self-reported behaviour: a controlled trial. Aust N Z J Psychiatry. 2011;45(7):549-57.

31. Kitchener BA, Jorm A. Mental health first aid training in a workplace setting: a randomized controlled trial. BMC Psychiatry. 2004;4:23.

32. Hallett J, Maycock B, Kypri K, Howat P, McManus A. Development of a webbased alcohol intervention for university students: processes and challenges. Drug Alcohol Rev. 2009:28(1):31-9.

33. Lobo R, Petrich M, Burns S. Supporting health promotion practitioner to undertake evaluation for program development. BMC Public Health. 2015; 14. doi: 10.1186/1471-2458-14-1315.

34. Burns SK, Portsmouth L. Health promotion. In: Felicity A, editor. Health Psychology and Behaviour in Australia. edn. Sydney: McGraw Hill; 2010. p. 457-86.

35. Howat PA, Maycock BR, Cross DS, Collins JM, Jackson L, Burns SK, James RW. Towards a more unified definition of health promotion. Health Promot J Austr. 2003;14(2):82-5.

36. Australian Institute of Health and Welfare. 2007 National Drug Strategy Household Survey: detailed findings. In: Drug statistics series no 22. Canberra: AlHW; 2008.

37. Saunders JB, Assland OG, Babor TF, De La Fuente JR, Grant M. Development of the Alcohol Use Disorders Identification Test (AUDIT): WHO collaborative project on early detection of persons with harmful alcohol consumption-II. Addiction. 1993;88:791-804.

38. McGee R, Kypri K. Alcohol-related problems experienced by university students in New Zealand. Aust N Z J Public Health. 2004;28:321-3.

39. Wechsler $H$, Lee JE, Kuo M, Seibring M, Nelson TF, Lee H. Trends in College binge drinking during a period of increased prevention efforts: findings from 4 Harvard School of Public Health College alcohol study surveys: 1993-2001. J Am Coll Heal. 2002:50(5):203-17.

40. Burns S, Crawford G, Hallett J, Jancey J, Portsmouth L, Hunt K, Longo J. Consequences of low risk and hazardous alcohol consumption among Australian university students in Australia and implications for Health Promotion Interventions. Open Journal of Preventive Medicine. 2015:5:1-13.

41. Ham LS, Stewart SH, Norton PJ, Hope DA. Psychometric assessment of the comprehensive effects of alcohol questionnaire: comparing a brief version to the original full scale. J Psychopathol Behav Assess. 2005;27(3):141-58.

42. Portney LG, Watkins MP. Foundations of clinical research: applications to practice. Connecticut: Appleton \& Lange; 1993.

43. Corbin WR, Iwamoto DK, Fromme K. Broad social motives, alcohol use, and related problems: mechanisms of risk from high school through college. Addict Behav. 2011;36:222-30.

44. Goodman RM, Steckler A, Kegler MC. Mobilizing organisations for health enhancement: theories of organisational change. In: Glanz K, Rimmer BK, Viswanath K, editors. Health behavior and health education. edn. San Francisco: Jossey-Bass; 2002.

45. Burns SK, Jancey J, Bowser N, Comfort J, Crawford G, Hallett J, Shields B, Portsmouth L. Moving forward: a cross sectional baseline study of staff and student attitudes towards a totally smoke free university campus. BMC Public Health. 2013;13:738.

46. Toomey TL, Lenk KM, Wadenaar AC. Environmental policies to reduce college drinking: an update of research findings. J Stud Alcohol Drugs. 2007; 68(2):208-19.

47. Stafford J, Allsop S, Daube M. From evidence to action: health promotion and alcohol. Health Promot J Austr. 2014;25:8-13.

48. Green J, Tones K, Cross R, Woodall J. Health promotion: planning and strategies. 3rd ed. London: Sage; 2015.

49. Kemm J. The limitations of 'evidence-based' public health. J Eval Clin Pract. 2006;12(3):319-24.

50. Green LW. Closing the chasm between research and practice: evidence of and for change. Health Promot J Austr. 2014;25(1):25-9.

\section{Submit your next manuscript to BioMed Central and we will help you at every step:}

- We accept pre-submission inquiries

- Our selector tool helps you to find the most relevant journal

- We provide round the clock customer support

- Convenient online submission

- Thorough peer review

- Inclusion in PubMed and all major indexing services

- Maximum visibility for your research

Submit your manuscript at www.biomedcentral.com/submit
Biomed Central 